\title{
Tocilizumab as monotherapy or combination therapy for treating active rheumatoid arthritis: a meta-analysis of efficacy and safety reported in randomized controlled trials
}

\author{
Xavier M. Teitsma ${ }^{*}$, Anne Karien A. Marijnissen, Johannes W. J. Bijlsma, Floris P. J. Lafeber \\ and Johannes W. G. Jacobs
}

\begin{abstract}
Background: Previous studies in patients with rheumatoid arthritis (RA) have shown that switching to tocilizumab (TCZ) monotherapy ( $T C Z_{M O N O}$ ) or combination therapy $\left(\mathrm{TCZ}_{\mathrm{COMB}}\right)$ with conventional synthetic disease-modifying anti-rheumatic drugs (csDMARDs) is efficacious in reducing disease activity in patients with inadequate response to csDMARDs. However, hitherto there is no consensus on whether $T C Z_{M O N O}$ is as effective as $T C Z_{C O M B I}$. The objective of this study was therefore to evaluate the efficacy and safety of $T C Z_{M O N O}$ versus add-on $T C Z_{C O M B I}$ and both TCZ therapies versus continuing the current csDMARD therapy, by performing a systematic review and meta-analyses.

Method: The MEDLINE, EMBASE and CENTRAL databases were searched until February 2016 for relevant randomized controlled trials (RCTs). We performed meta-analyses of Disease Activity Score in 28 joints (DAS28 < 2.6), American College of Rheumatology (ACR) 20/50/70 responses, adverse events (AEs) and serious AEs (SAEs) to compare the three different strategies, whereas a random-effect model was used for pooling relative risks (RR) and $95 \%$ confidence intervals (Cl). In addition, sensitivity analyses were performed for evaluating differences in study duration.

Results: In total, 13 RCTs were included in the meta-analysis, involving 6679 patients. When comparing both TCZ strategies, a marginally greater proportion of patients achieving DAS28 < 2.6 (RR 1.21; $95 \% \mathrm{Cl} 1.09,1.36$ ) and ACR50 response (RR 1.14; $95 \% \mathrm{Cl} 1.03,1.26)$ was found in favor of the TCZ COMBI $_{2}$ strategy. However, the risk of SAEs was also significantly higher using this strategy (RR 1.40; $95 \% \mathrm{Cl} 1.03,1.92, p=0.03$ ). Pooled effect estimates showed statistical superiority of switching to either TCZ strategy compared to continuing CSDMARD therapy.
\end{abstract}

Conclusions: In the management of active RA, almost similar efficacy can be expected in patients unable to tolerate CsDMARDs, who switch to TCZ $Z_{\text {MONO }}$ compared to inadequate responders switching to add-on TCZ ${ }_{C O M B}$. Although $\mathrm{TCZ}_{\mathrm{COMBI}}$ is marginally superior to $\mathrm{TCZ}_{\mathrm{MONO}}$ in achieving DAS28 $<2.6$ and ACR50 response, this is at the cost of an increased risk of SAEs.

Keywords: Rheumatoid arthritis, Tocilizumab, Interleukin-6, Disease-modifying anti-rheumatic drugs, Biological

\footnotetext{
* Correspondence: x.m.teitsma@umcutrecht.nl

Department of Rheumatology and Clinical Immunology, University Medical

Center Utrecht, Heidelberglaan 100, Utrecht 3584 CX, Netherlands
}

(c) 2016 The Author(s). Open Access This article is distributed under the terms of the Creative Commons Attribution 4.0 International License (http://creativecommons.org/licenses/by/4.0/), which permits unrestricted use, distribution, and reproduction in any medium, provided you give appropriate credit to the original author(s) and the source, provide a link to the Creative Commons license, and indicate if changes were made. The Creative Commons Public Domain Dedication waiver (http://creativecommons.org/publicdomain/zero/1.0/) applies to the data made available in this article, unless otherwise stated. 


\section{Background}

In the management of rheumatoid arthritis (RA), conventional synthetic disease-modifying anti-rheumatic drugs (csDMARDs) are recommended as first-line treatment in DMARD-naïve patients for achieving remission [1-3]. Patients who have inadequate response to csDMARDs as defined by not achieving the treatment target should receive add-on therapy with a biological DMARD (bDMARD) if they have factors linked to poor prognosis (e.g., early joint damage or seropositivity). However, data obtained from large cohort studies reveal that approximately one-third of patients with RA discontinue all csDMARDs and initiate bDMARD monotherapy, mainly because of intolerance or noncompliance in taking the csDMARD [4-6]. Adverse events (AEs) are the main reason for withdrawal (>70\% of patients), with gastrointestinal symptoms being most frequently observed ( $>30 \%$ of patients) $[6,7]$.

For patients in whom continuing csDMARD therapy is not feasible, it is important to know the effectiveness and safety of switching to bDMARD monotherapy. To this day, there is no clear preference as to which biologic agent (e.g., tumor necrosis factor inhibitors (infliximab, etanercept, adalimumab, certolizumab pegol, golimumab), rituximab (targeting B-cells), abatacept (targeting $\mathrm{T}$ cells) or tocilizumab (TCZ) (inhibiting interleukin 6 signaling [8]) is preferable if monotherapy must be initiated, because of a lack of head-to-head comparisons. In ADACTA, [9] a randomized, double-blind, controlled study, TCZ was shown to be superior to adalimumab in patients requiring monotherapy and could thus potentially be suitable as first-line biologic therapy. To our knowledge, this is hitherto the only bDMARD monotherapy superiority study reported. Several randomized phase III studies have shown that switching to TCZ monotherapy or combination therapy is efficacious in achieving rapid and sustained improvements within patients who do not achieve the treatment aim with csDMARD therapy [10-20]. However, there is no consensus as to whether TCZ as monotherapy is as effective as TCZ combined with csDMARDs. Although several studies have compared switching to TCZ monotherapy with add-on combination therapy, this has not yet been analyzed in meta-analyses. The objective of this study was to evaluate the efficacy and safety in patients with RA of TCZ monotherapy versus add-on TCZ combination therapy, and both TCZ therapies versus continuing the current csDMARD therapy, by performing a systematic review and meta-analyses.

\section{Methods}

\section{Systematic literature search and study selection}

A systematic review of the literature was conducted according to the Preferred Reporting Items for Systematic Reviews and Meta-analyses (PRISMA) statement protocol [21]. Relevant publications were identified using MEDLINE,
EMBASE and Cochrane Central Register of Controlled Trials (CENTRAL). The following key search medical subject heading $(\mathrm{MeSH})$ terms were selected with the help of a librarian: "Rheumatoid Arthritis"[MeSH] OR "Rheumatoid Arthritis"[tiab] AND ("Tocilizumab”[Suppl. Concept] OR “Tocilizumab”[tiab] OR "Interleukin-6"[MeSH] OR "Interleukin-6"[tiab] OR "IL-6"[tiab] OR "IL-6 receptor inhibitor"[tiab] OR "MRA"[tiab]) AND ("Randomized controlled trial" [MeSH] OR "randomized controlled trial"[tiab] OR "Clinical trial” $[\mathrm{MeSH}]$ OR "Clinical trial”[tiab] OR “RCT"[tiab]).

The full search strategy can be found in Additional file 1. All titles and abstracts were independently screened by two review authors (XMT and ACAM) and studies were included if: (1) they were RCTs or quasi-RCTs comparing TCZ $8 \mathrm{mg} / \mathrm{kg} \quad\left(\mathrm{TCZ}_{\mathrm{MONO}}\right)$ versus $\mathrm{TCZ} \quad 8 \mathrm{mg} / \mathrm{kg}+$ csDMARD (TCZ $\mathrm{TCMBI}_{\mathrm{CO}}$ ), TCZ $\mathrm{TONO}_{\mathrm{MON}}$ versus $\mathrm{csDMARD}$ or $\mathrm{TCZ}_{\mathrm{COMBI}}$ versus csDMARD; (2) patients met the 1987 American College of Rheumatology (ACR) or 2010 ACR/ European League against Rheumatism (EULAR) RA classification criteria [22, 23] and if they (3) reported ACR 20/ $50 / 70$ responses, Disease Activity Score in 28 joints (DAS28), incidence of AEs and serious AEs (SAEs) within $\leq 52$ weeks. Studies were excluded if: (1) TCZ was compared to another bDMARD; (2) only DMARD-naive patients were included; (3) study participants were younger than 18 years; and (4) articles had not been published in the English language. If needed, the full text of the article was obtained for further assessment of eligibility. In addition, references from relevant articles were also reviewed for eligible citations. Articles not available were requested from the authors.

\section{Data extraction and outcome assessment}

We abstracted the following data from each study that was included: design, duration, number of enrolled patients and baseline characteristics (age, gender, symptom duration, previous csDMARD and bDMARD use, erythrocyte sedimentation rate (ESR), C-reactive protein (CRP), DAS28 and Health Assessment Questionnaire score (HAQ). Outcome measurements of DAS28 remission (<2.6), ACR 20/50/70 responses, AEs and SAEs were assessed in meta-analyses. The methodological quality of the studies was independently evaluated by two review authors (XMT and ACAM) using the Cochrane Collaboration recommendations for assessing risk of bias [24]. Information was gathered and assessed on the use of random sequence generation, allocation concealment, blinding (of participants, personnel and outcome assessors), incomplete outcome data, selective reporting and sources of potential bias. Discrepancies between the two review authors were resolved by consensus with a third reviewer (JWGJ). 


\section{Statistical analysis}

Meta-analyses were performed for the following treatmentcontrol combinations: (1) $\mathrm{TCZ}_{\mathrm{MONO}}$ versus $\mathrm{TCZ}_{\mathrm{COMBI}}$; (2) $\mathrm{TCZ}_{\mathrm{MONO}}$ versus csDMARD; and (3) $\mathrm{TCZ}_{\mathrm{COMBI}}$ versus csDMARD. Efficacy and safety measures were modeled as binary outcomes and we used a random-effects model by employing the Mantel-Haenszel method for pooling relative risks (RR) and $95 \%$ confidence intervals (CI). During the study selection we noticed large heterogeneity between studies; hence a random-effects model was applied [25]. To analyze the sensitivity of our meta-analyses, we performed sensitivity analyses by excluding studies not reporting outcome measures at week 24 , to evaluate if differences in effect sizes between studies occurred due to the variability in study duration. The $I$ squared statistic $\left(I^{2}\right)$ was calculated to quantify heterogeneity between studies. Furthermore, publication bias was assessed by visual inspection of asymmetry in funnel plots, and relative risks were plotted on a logarithmic scale [26]. $P$ values $<0.05$ were considered statistically significant. Statistical analyses were performed with Review Manager version 5.3 (Cochrane Collaboration, Oxford, UK).

\section{Results}

Literature search and study characteristics

The first search was performed in May 2015 and after removing duplicates we retrieved 583 studies, of which 39 full articles were assessed for eligibility (Fig. 1). Of those studies, 11 fulfilled the inclusion criteria: Maini et al. 2006 (CHARISMA) [10], Nishimoto et al. 2007 (SAMURAI) [11], Emery et al. 2008 (RADIATE) [12], Smolen et al. 2008 (OPTION) [14], Genovese et al. 2008 (TOWARD) [13], Nishimoto et al. 2009 (SATORI) [15], Jones et al. 2010 (AMBITION) [16], Kremer et al. 2011 (LITHE) [17], Yazici et al. 2012 (ROSE) [18], Weinblatt et al. 2013 (ACT-STAR) [20] and Dougados et al. 2013 (ACTRAY) [19]. The search was updated in February 2016 and yielded two additional studies fulfilling the inclusion criteria: Burmester et al. 2015 (FUNCTION) [27] and Kaneko et al. 2016 (SURPRISE) [28].

Patient demographics and baseline characteristics are summarized in Table 1. In total 6679 patients were included in the meta-analysis (1298 patients treated with $\mathrm{TCZ}_{\mathrm{MONO}} 3077$ patients treated with $\mathrm{TCZ}_{\mathrm{COMBI}}$ and 2204 patients treated with csDMARD therapy). Demographic characteristics were comparable between studies with respect to age, gender, ESR, CRP and DAS28. Average symptom duration ranged from 4 to 14 years, except in three studies $[10,11,27]$ of patients with early RA (of duration $\leq 2$ years) only. Furthermore, eight studies [12-16, 18-20] reported 24-week results for efficacy and safety outcomes, four studies $[11,17,27,28]$ reported 52-week results and one study [10] reported outcomes at week 16 . For conducting our meta-analyses, we addressed the corresponding authors of these studies and F Hoffmann-La Roche,

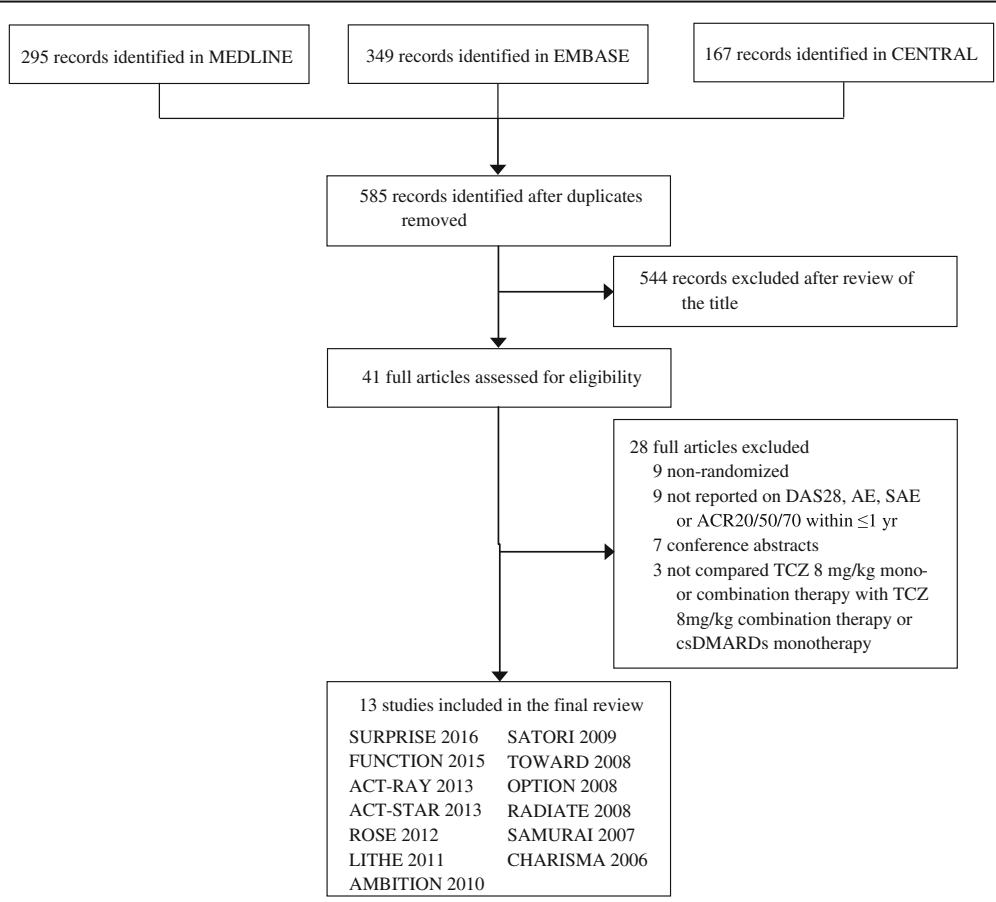

Fig. 1 Preferred Reporting Items for Systematic Reviews and Meta-analyses flow diagram of studies included in the review. ACR American College of Rheumatology, DAS28 Disease Activity Score in 28 joints, AE adverse event, SAE serious adverse event, TCZ tocilizumab, CSDMARDs diseasemodifying anti-rheumatic drugs 
Table 1 Study design and baseline characteristics of study participants presented per treatment-control combination

\begin{tabular}{|c|c|c|c|c|c|c|c|c|c|c|c|c|c|}
\hline Study & $\begin{array}{l}\text { Treatment } \\
\text { arms }\end{array}$ & Design & $\begin{array}{l}\text { Study length } \\
\text { (weeks) }\end{array}$ & $\begin{array}{l}\text { Enrolled } \\
\text { patients }(n)\end{array}$ & $\begin{array}{l}\text { csDMARD-naïve at } \\
\text { baseline (yes, no) }\end{array}$ & $\begin{array}{l}\text { Previous biologic } \\
\text { therapy }(\%)\end{array}$ & $\begin{array}{l}\text { Mean age } \\
\text { (years) }\end{array}$ & $\begin{array}{l}\text { Female } \\
(\%)\end{array}$ & $\begin{array}{l}\text { Symptom } \\
\text { duration (years) }\end{array}$ & $\operatorname{ESR}(\mathrm{mm} / \mathrm{h})$ & CRP (mg/l) & DAS28 & $\mathrm{HAQ}$ \\
\hline \multicolumn{14}{|l|}{$\mathrm{TCZ}_{\text {COMBI }}$ vs. TCZ MONO } \\
\hline \multirow[t]{2}{*}{ SURPRISE (2016) } & TCZ & Open label & 52 & 115 & No & 0 & $56(12)$ & 87 & $4(3)$ & $41(28)$ & $12(15)$ & $5.1(1)$ & $1.0(0.7)$ \\
\hline & $\mathrm{TCZ}_{\mathrm{MONO}}$ & & & 111 & & & $56(3)$ & 87 & $4(3)$ & $45(30)$ & $18(26)$ & $5.3(1.2)$ & $1.0(0.7)$ \\
\hline \multirow[t]{2}{*}{ FUNCTION (2015) } & $\mathrm{TCZ} Z_{\mathrm{COMBI}}$ & Double-blind & 52 & 291 & $\mathrm{No}^{f}$ & 0 & $50(14)$ & 79 & $6(6)^{9}$ & $53(30)$ & $26(30)$ & $6.7(1.1)$ & $1.5(0.6)$ \\
\hline & $\mathrm{TCZ}_{\mathrm{MONO}}$ & & & 292 & & & $50(12)$ & 75 & $6(6)^{g}$ & $51(28)$ & $25(32)$ & $6.7(1.0)$ & $1.6(0.7)$ \\
\hline \multirow[t]{2}{*}{ ACT-RAY (2013) } & $\mathrm{TCZ}$ СOMBI & Open-label, & 24 & 277 & No & 0 & $53(13)$ & 82 & $8(8)$ & NR & NR & $6.3(1)$ & $1.5(0.7)$ \\
\hline & TCZ MONO & & & 276 & & & $54(12)$ & 79 & $8(8)$ & & & $6.4(1)$ & $1.5(0.6)$ \\
\hline \multirow[t]{2}{*}{$\operatorname{ACT-STAR~}(2013)^{a}$} & $\mathrm{TCZ} Z_{\mathrm{COMBI}}$ & Open-label & 24 & 360 & No & 67 & $54(12)$ & 78 & $11(9)$ & NR & $14(21)$ & $5.5(1)$ & NR \\
\hline & TCZ MONO & & & 163 & & 87 & $54(13)$ & 80 & $14(10)$ & & $19(33)$ & $6.0(1)$ & \\
\hline \multirow[t]{2}{*}{ CHARISMA (2006) } & $\mathrm{TCZ} Z_{\mathrm{COMBI}}$ & Double-blind & 16 & 50 & No & 14 & 50 (NR) & 78 & $11(\mathrm{NR})^{\mathrm{c}}$ & 39 (NR) & 24 (NR) & 6.5 (NR) & NR \\
\hline & $\mathrm{TCZ}$ MONO & & & 52 & & & 50 (NR) & 73 & $9(N R)^{c}$ & 39 (NR) & 22 (NR) & 6.4 (NR) & \\
\hline \multicolumn{14}{|l|}{ TCZ COMBI vs. CsDMARD } \\
\hline \multirow[t]{2}{*}{ FUNCTION (2015) } & $\mathrm{TCZ} Z_{\mathrm{COMBI}}$ & Double-blind & 52 & 291 & No & 0 & $50(14)$ & 79 & $6(6)^{c}$ & $53(30)$ & $26(30)$ & $6.7(1.1)$ & $1.5(0.6)$ \\
\hline & csDMARD & & & 289 & & & $50(13)$ & 80 & $5(6)^{c}$ & $50(27)$ & $23(27)$ & $6.6(1.0)$ & $1.5(0.7)$ \\
\hline \multirow[t]{2}{*}{ ROSE (2012) } & $\mathrm{TCZ}$ СомBI & Double-blind & 24 & 409 & No & 38 & $55(12)$ & 80 & $9(9)$ & $46(24)$ & $17(21)$ & $6.5(1)$ & $4.1(1.7)^{h}$ \\
\hline & cSDMARD & & & 205 & & 38 & $56(12)$ & 84 & $9(9)$ & $47(22)$ & $17(22)$ & $6.6(1)$ & $4.0(2.1)^{\mathrm{h}}$ \\
\hline \multirow[t]{2}{*}{ LITHE $(2011)^{a}$} & $\mathrm{TCZ} Z_{\mathrm{COMBI}}$ & Double-blind $^{d}$ & 52 & 398 & No & 11 & $53(12)$ & 82 & 9 (NR) & $46(25)$ & $23(26)$ & $6.6(1)$ & $1.5(0.6)$ \\
\hline & csDMARD & & & 393 & & 12 & $51(12)$ & 83 & $9(N R)$ & $47(25)$ & $22(25)$ & $6.5(1)$ & $1.5(0.6)$ \\
\hline \multirow[t]{2}{*}{ TOWARD (2008) } & $\mathrm{TCZ} Z_{\mathrm{COMBI}}$ & Double-blind & 24 & 803 & No & NS & $53(13)$ & 81 & $10(9)$ & $48(28)$ & $26(32)$ & $6.7(1)$ & $1.5(0.6)$ \\
\hline & CSDMARD & & & 413 & & & $54(13)$ & 84 & $10(9)$ & $49(28)$ & $26(47)$ & $6.6(1)$ & $1.5(0.6)$ \\
\hline \multirow[t]{2}{*}{ OPTION (2008) } & $\mathrm{TCZ} Z_{\mathrm{COMBI}}$ & Double-blind & 24 & 205 & No & 5 & $51(12)$ & 85 & $8(7)$ & $51(27)$ & $26(26)$ & $6.8(1)$ & $1.6(0.6)$ \\
\hline & CSDMARD & & & 204 & & 9 & $51(12)$ & 78 & $8(7)$ & $50(26)$ & $24(28)$ & $6.8(1)$ & $1.5(0.6)$ \\
\hline \multirow[t]{2}{*}{ RADIATE (2008) $)^{a}$} & $\mathrm{TCZ} Z_{\mathrm{COMBI}}$ & Double-blind & 24 & 170 & No & 100 & $54(13)$ & 84 & $13(9)$ & $49(28)$ & $28(33)$ & $6.8(1)$ & $1.7(0.6)$ \\
\hline & CsDMARD & & & 158 & & & $53(13)$ & 79 & $11(9)$ & $55(33)$ & $37(41)$ & $6.8(1)$ & $1.7(0.6)$ \\
\hline \multirow[t]{2}{*}{ CHARISMA (2006) } & $\mathrm{TCZ}$ СомBI & Double-blind & 16 & 50 & No & 14 & $50(\mathrm{NR})$ & 78 & $11(\mathrm{NR})^{\mathrm{c}}$ & 39 (NR) & 24 (NR) & $6.5(\mathrm{NR})$ & $N R$ \\
\hline & CSDMARD & & & 49 & & & $51(N R)$ & 78 & $11(\mathrm{NR})^{\mathrm{C}}$ & 43 (NR) & $32(N R)$ & $6.8(N R)$ & \\
\hline \multicolumn{14}{|l|}{ TCZ MONO Vs. CSDMARD } \\
\hline \multirow[t]{2}{*}{ FUNCTION (2015) } & TCZ MONO & Double-blind & 52 & 292 & No & 0 & $50(12)$ & 75 & $6(6)^{c}$ & $51(28)$ & $25(32)$ & $6.7(1.0)$ & $1.6(0.7)$ \\
\hline & csDMARD & & & 289 & & & $50(13)$ & 80 & $5(6)^{c}$ & $50(27)$ & $23(27)$ & $6.6(1.0)$ & $1.5(0.7)$ \\
\hline \multirow[t]{2}{*}{ AMBITION (2010) } & $\mathrm{TCZ}_{\mathrm{MONO}}$ & Double-blind & 24 & 286 & No & 8 & $51(13)$ & 83 & $6(8)$ & $50(28)$ & $30(33)$ & $6.8(1)$ & $1.6(0.7)$ \\
\hline & csDMARD & & & 284 & & 7 & $50(13)$ & 79 & $6(8)$ & $49(26)$ & 31 (34) & $6.8(1)$ & $1.5(0.6)$ \\
\hline
\end{tabular}


Table 1 Study design and baseline characteristics of study participants presented per treatment-control combination (Continued)

\begin{tabular}{|c|c|c|c|c|c|c|c|c|c|c|c|c|c|}
\hline \multirow[t]{2}{*}{ SATORI (2009) } & $\mathrm{TCZ}_{\mathrm{MONO}}$ & Double-blind & 24 & 61 & No & NS & $53(11)$ & 90 & $9(8)$ & $52(28)$ & $30(20)$ & $6.1(1)$ & NR \\
\hline & csDMARD & & & 64 & & & $51(12)$ & 75 & $9(7)$ & $52(24)$ & $32(26)$ & $6.2(1)$ & \\
\hline \multirow[t]{2}{*}{ SAMURAI (2007) } & TCZ MONO & Open-label $^{e}$ & 52 & 157 & No & NS & $53(12)$ & 80 & $2(1)$ & $71(28)$ & $47(29)$ & $6.5(1)$ & $N R$ \\
\hline & csDMARD & & & 145 & & & $53(13)$ & 82 & $2(1)$ & $71(25)$ & $49(29)$ & $6.4(1)$ & \\
\hline \multirow[t]{2}{*}{ CHARISMA (2006) } & $\mathrm{TCZ}_{\mathrm{MONO}}$ & Double-blind & 16 & 52 & No & 14 & 50 (NR) & 73 & $9(N R)^{c}$ & 39 (NR) & 22 (NR) & 6.4 (NR) & $N R$ \\
\hline & csDMARD & & & 49 & & & 51 (NR) & 78 & $11(\mathrm{NR})^{c}$ & 43 (NR) & 32 (NR) & 6.8 (NR) & \\
\hline
\end{tabular}

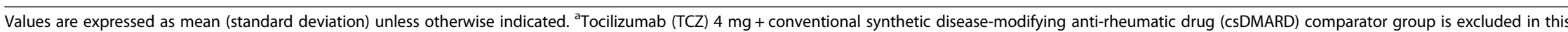

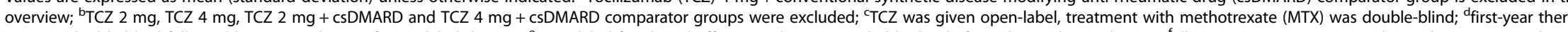
apy was double-blind followed by a second year of open-label therapy; ${ }^{\circ}$ open-label for clinical efficacy endpoints, single-blind only for radiographic evaluation; ${ }^{f}$ all patients were MTX-naïve, but only approximately $80 \%$ were entirely csDMARD-naïve; ${ }^{9}$ months; ${ }^{\text {h}}$ Health Assessment Questionnaire-physical function (HAQ-PF) score. TCZ tocilizumab, ESR erythrocyte sedimentation rate, CRP C-reactive protein, DAS28 Disease Activity Score in 28 joints, NS percentage not specified, NR not reported 
manufacturer of TCZ and partial owner of the data, to obtain numerical data on the outcome measurements at week 24 . For the 52-week studies we were able to obtain the 24week data on efficacy outcomes; safety assessments were not available (except for the LITHE [17]).

Most studies included [10, 12, 14-17, 19, 27, 28] used methotrexate (MTX) as the csDMARD and folic acid ( $\geq 5 \mathrm{mg} /$ week) was given to all patients to minimize MTX-related toxicity, except in two studies [15, 19] in which only 51-81\% of the patients received folic acid. Folate supplementation was not reported in two other studies [27, 28]. Before study entry, all patients were on stable doses of MTX or other csDMARDs for $\geq 4$ weeks before switching to the $\mathrm{TCZ}_{\mathrm{MONO}}$ or $\mathrm{TCZ}_{\mathrm{COMBI}}$ strategy, except in the FUNCTION [27] study in which the majority $(81 \%)$ of patients were DMARD-naive, and the ACTSTAR [20] study in which patients were on bDMARD monotherapy before switching to the $\mathrm{TCZ}_{\mathrm{MONO}}$ strategy. There were also differences between studies in prior antitumor necrosis factor alpha (aTNF $\alpha$ ) treatment. In four studies $[10,14,16,17]$, only a small proportion (5-14 \%) of the patients had received aTNF $\alpha$ medication prior to inclusion, in contrast to other studies $[12,18,20]$ in which $38-100 \%$ of patients had received aTNF $\alpha$. In several studies $[11,13,15]$, aTNF $\alpha$ treatment was allowed before the start of the study; however, this proportion was not specified and in the ACT-RAY [19], FUNCTION [27] and SURPRISE [28] studies, patients were excluded if they had previously received aTNF $\alpha$ treatment. In the studies in which prior aTNF $\alpha$ treatment was allowed, washout periods were applied before study entry to reduce treatment effects, except in the ACT-STAR study [20].

The most commonly reported AEs in the studies included in our meta-analyses were infections (e.g., skin and respiratory infections), skin disorders (e.g., rash) and gastrointestinal symptoms (e.g., nausea). The studies reported an incidence of AEs and SAEs in patients treated with $\mathrm{TCZ}_{\mathrm{MONO}}$ ranging from 59 to $92 \%$ and from 4 to $18 \%$, respectively $[10,11,15,16,19,20]$. For $\mathrm{TCZ}_{\mathrm{COMBI}}$, these ranges were 54 to $84 \%$ and 6 to $14 \%$, respectively, $[10,12-14,18-20]$ and for csDMARD therapy 47 to $82 \%$ and 3 to $13 \%$, respectively $[10-16,18]$.

\section{Efficacy outcomes \\ DAS28 $<2.6$}

Forest plots of DAS28 are shown in Fig. 2. In the TCZ monotherapy and combination strategy, pooled effect estimates for achieving remission were significantly higher (RR 3.95; $95 \%$ CI 2.23, 7.00, $p<0.001$ and RR 8.77; $95 \%$ CI $4.10,18.75, p<0.001$, respectively) compared to csDMARD therapy. On comparison of the two TCZ strategies, the effect estimate was significantly higher (RR 1.21; $95 \% \mathrm{CI}$ $1.09,1.36, p<0.001)$ for the combination strategy.

\section{ACR20 response}

Forest plots of the ACR responses are shown in Additional file 2. Pooled effect estimates for achieving ACR20 response were significantly higher for both the $\mathrm{TCZ}_{\mathrm{MONO}}(\mathrm{RR} 1.68$; $95 \%$ CI 1.21, 2.32, $p=0.002$ ) and $\mathrm{TCZ}_{\mathrm{COMBI}}$ (RR 2.10; $95 \%$ CI 1.48, 2.99, $p<0.001)$ strategy, when compared to csDMARD therapy. There was no difference between the two TCZ strategies $(p=0.11)$.

\section{ACR50 response}

The proportion of ACR50 responders was statistically higher with both TCZ strategies compared to CSDMARD therapy $\left(\mathrm{TCZ}_{\mathrm{MONO}}\right.$ : RR 1.87; $95 \%$ CI 1.19, 2.95, $p=0.007$ and $\mathrm{TCZ}_{\mathrm{COMBI}}$ : RR 3.00; $95 \%$ CI 1.80, 4.99, $\left.p<0.001\right)$. Furthermore, patients treated with the add-on $\mathrm{TCZ}_{\mathrm{COMBI}}$ strategy achieved an ACR50 response significantly more often than with the $\mathrm{TCZ}_{\mathrm{MONO}}$ strategy; however, this effect estimate was relatively small (RR 1.14; $95 \%$ CI 1.03, $1.26, p=0.008)$.

\section{ACR70 response}

The pooled effect estimates of ACR70 response rates were significantly higher in patients treated with the $\mathrm{TCZ}_{\mathrm{MONO}}$ and $\mathrm{TCZ}_{\mathrm{COMBI}}$ strategy compared to patients treated with csDMARD therapy (RR 2.11; $95 \%$ CI 1.18, 3.78, $p=0.01$ and RR 5.32; 95 \% CI 2.31, 12.25, $p<0.001$, respectively). There was no statistically significant difference between the two TCZ strategies $(p=0.14)$.

\section{Safety outcomes \\ Adverse events}

For both TCZ strategies, the pooled risk estimates for experiencing one or more AE during treatment was significantly higher compared to csDMARD therapy ( $\mathrm{TCZ}_{\mathrm{MONO}}$ : RR 1.08; $95 \%$ CI 1.01, 1.15, $p=0.03$; $\mathrm{TCZ}_{\mathrm{COMBI}}$ : RR 1.12; $95 \%$ CI 1.06, 1.18, $p<0.001$, Fig. 3). In the meta-analyses of $\mathrm{TCZ}_{\mathrm{MONO}}$ versus $\mathrm{TCZ}_{\mathrm{COMBI}}$, there was no statistically significant difference between the strategies $(p=0.17)$.

SAEs occurred more frequently in the $\mathrm{TCZ}_{\mathrm{MONO}}(\mathrm{RR}$

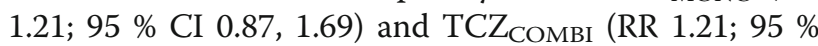
CI $0.91,1.60)$ strategy compared to csDMARD therapy (Fig. 4). However, this increased risk was not statistically significant for either TCZ strategy ( $p=0.26$ and $p=0.19$, respectively). When comparing the incidence of SAEs with the $\mathrm{TCZ}_{\mathrm{MONO}}$ and $\mathrm{TCZ}_{\mathrm{COMBI}}$ strategies, the pooled risk estimate was significantly higher with the combination strategy (RR 1.40; $95 \%$ CI 1.03, 1.92, $p=0.03$ ).

\section{Publication bias}

We found no clear indication of publication bias on visual inspection of funnel plots (see Additional file 3). The effect estimates of most studies were within the expected $95 \%$ CI, indicating no clear pattern of bias. However, assessment of publication bias in such a small number of 


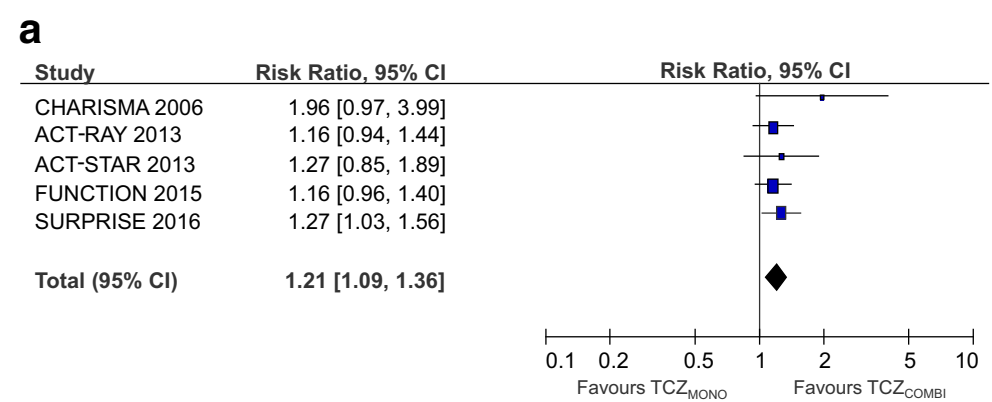

b

\begin{tabular}{|c|c|c|c|}
\hline Study & Risk Ratio, $95 \% \mathrm{Cl}$ & \multicolumn{2}{|c|}{ Risk Ratio, $95 \% \mathrm{Cl}$} \\
\hline CHARISMA 2006 & $3.43[1.21,9.69]$ & & 7 \\
\hline OPTION 2008 & $33.26[4.65,237.76]$ & & $\rightarrow$ \\
\hline RADIATE 2008 & $16.15[5.15,50.67]$ & & $\longrightarrow$ \\
\hline TOWARD 2008 & $10.33[5.86,18.22]$ & & + \\
\hline LITHE 2011 & $8.83[4.40,17.74]$ & & \\
\hline ROSE 2012 & $22.29[5.60,88.80]$ & & $\longrightarrow$ \\
\hline FUNCTION 2015 & $2.99[2.21,4.05]$ & & 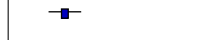 \\
\hline Total $(95 \% \mathrm{Cl})$ & $8.77[4.10,18.75]$ & & \\
\hline & & $\begin{array}{lc} & 1 \\
0.02 & 0.1 \\
\text { Favours csDMARD }\end{array}$ & $\begin{array}{ccc}1 & 10 & 50 \\
& \text { Favours TCZ }\end{array}$ \\
\hline
\end{tabular}

C

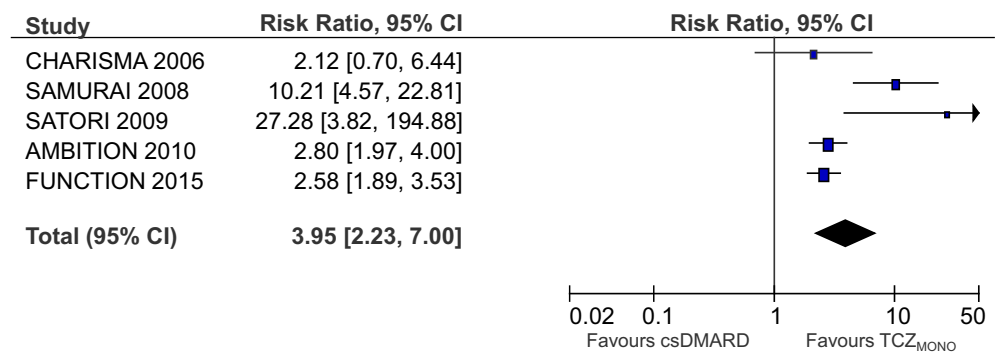

Fig. 2 Forest plots of Disease Activity Score remission (<2.6) assessed in 28 joints (DAS28) comparing tocilizumab combination therapy $\left(T C Z_{\text {COMB }}\right)$ with tocilizumab monotherapy ( $\left.T C Z_{M O N O}\right)(\mathbf{a})$, TCZ TCZ MONO with a cSDMARD (c)

studies remains controversial and should be interpreted with caution [29].

\section{Sensitivity analysis}

The pooled effect estimates of the sensitivity analyses are shown in Table 2; studies were excluded if they did not report 24-week results. In the efficacy and safety meta-analysis of $\mathrm{TCZ}_{\mathrm{COMBI}}$ versus $\mathrm{TCZ}_{\mathrm{MONO}}$, one [10] and three studies $[10,27,28]$ were excluded, respectively. The effect estimates of the efficacy outcomes remained relatively unchanged; however, the pooled risk for SAEs changed from being significant (RR 1.40; $95 \%$ CI $1.03,1.92, p=0.03$ ) to non-significant (RR 1.34; $95 \%$ CI $0.79,2.27, p=0.27$ ), indicating the two TCZ strategies were equally safe. In the efficacy and safety metaanalysis of $\mathrm{TCZ}_{\mathrm{COMBI}}$ versus a csDMARD, one [10] and two studies $[10,27]$ were excluded, respectively; the sensitivity analyses showed greater effect estimates for DAS28 $<2.6$ and ACR20/50/70 responses in favor of the TCZ strategy; the risk of AEs and SAEs did not change significantly. In the meta-analysis of $\mathrm{TCZ}_{\mathrm{MONO}}$ versus a csDMARD, one study [10] was excluded from analysis of the efficacy outcomes and three studies $[10,11,27]$ from analysis of the safety outcomes; the pooled risk of AEs changed from being significant (RR 1.08; $95 \%$ CI 1.01, $1.15, p=0.03$ ) to non-significant (RR 1.13; $95 \%$ CI 0.92, $1.39, p=0.24)$ in favor of the TCZ strategy.

\section{Assessment of heterogeneity}

A detailed description of the heterogeneity per metaanalysis is presented in Additional file 4. Heterogeneity $\left(I^{2}\right)$ was the lowest in the $\mathrm{TCZ}_{\mathrm{COMBI}}$ versus $\mathrm{TCZ}_{\mathrm{MONO}}$ comparison, indicating minimal differences in effect sizes between studies. However, in the majority of the other 
a

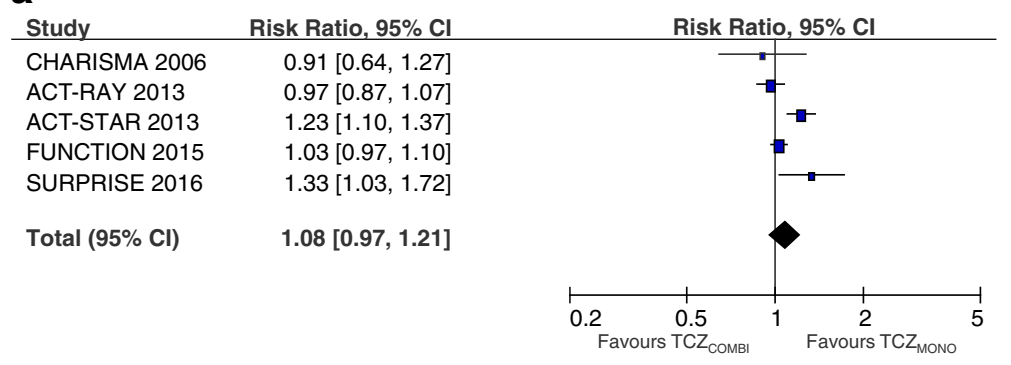

b

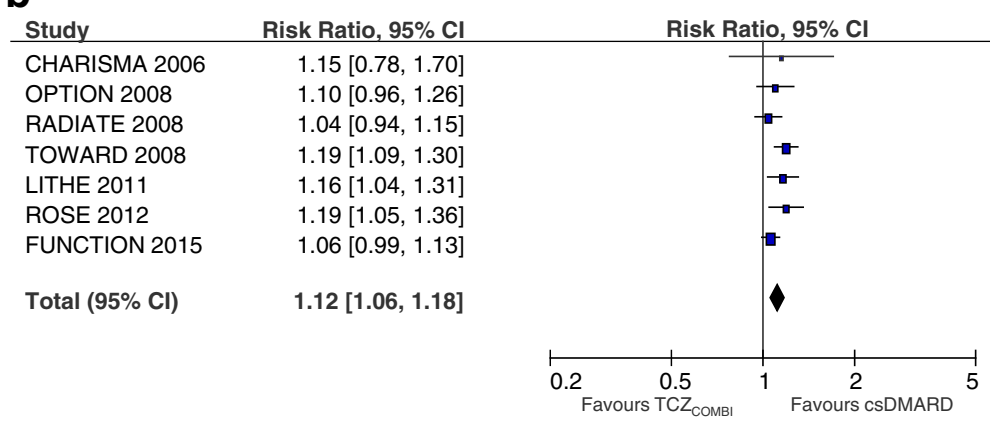

C

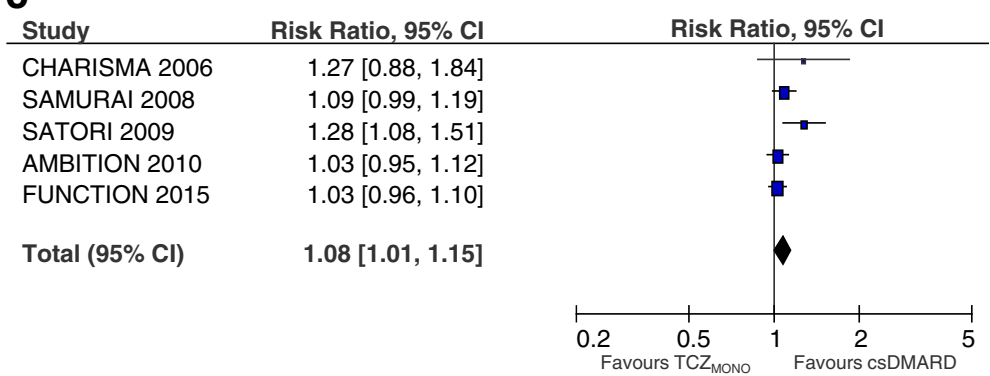

Fig. 3 Forest plots of adverse events comparing tocilizumab combination therapy ( $\left.T C Z_{C O M B}\right)$ with tocilizumab monotherapy (TCZ $\left.{ }_{M O N O}\right)$ (a), $\mathrm{TCZ}_{\mathrm{COMBI}}$ with a conventional synthetic disease-modifying anti-rheumatic drug (CsDMARD) (b) and TCZ $\mathrm{MONO}_{\text {with a }}$ CSDMARD (c)

meta-analyses we found substantial heterogeneity $(>50 \%)$. Furthermore, the results of our sensitivity analyses show that heterogeneity between studies was even slightly increased by excluding studies reporting outcome measures other than at 24 weeks, which indicates that the betweenstudy variation in our meta-analyses was not majorly affected by the differences in study duration.

\section{Risk of bias assessment}

The risk of bias assessment is shown in Additional file 5 . To appraise the generalizability of our findings, we assessed the validity of the studies included. Generally, there was a low risk of selection bias because of adequate allocation concealment, except for the OPTION study [14]. In this study, the randomization list was provided by $\mathrm{F}$ Hoffmann-La Roche, the manufacturer of TCZ. The risk of performance and detection bias was also low because studies were double-blinded, except for the ACT-RAY, ACT-STAR, SURPRISE and SAMURAI studies, which were open-label $[19,20,28]$ and singleblinded [11] studies, respectively. Most authors received consulting and/or speaking fees, honoraria, held a patent for TCZ, held stock or stock options with the manufacturer or were employees of F Hoffmann-La Roche. Also, except for the SURPRISE study [28], all studies were directly supported by F Hoffmann-La Roche or Chugai Pharmaceutical. Although vested interests do not necessarily lead to bias or impaired study methodology, these aspects should, however, be weighed in the balance in coming to a conclusion when determining the efficacy and safety of TCZ in patients with RA.

\section{Discussion}

This is the first meta-analysis comparing the efficacy and safety of TCZ monotherapy versus TCZ add-on combination therapy in patients with RA. Our results 
a

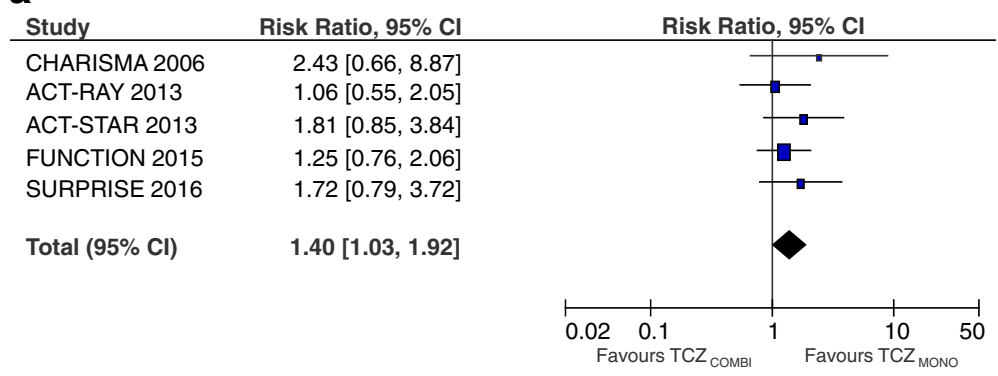

b

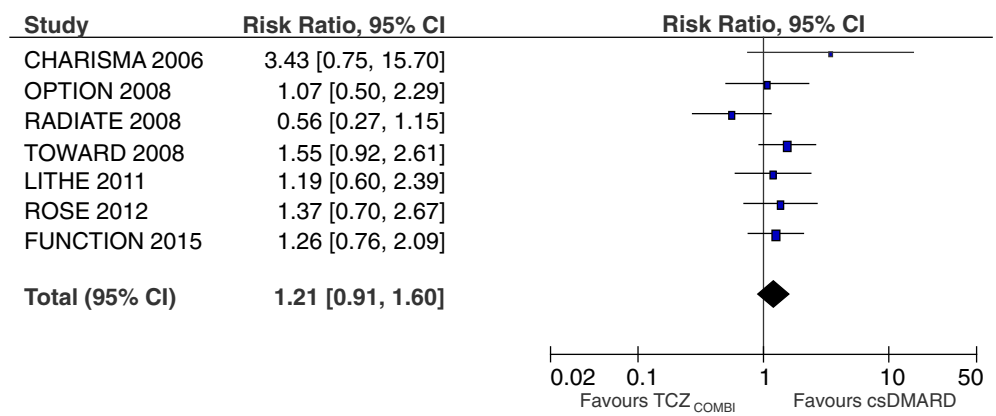

C

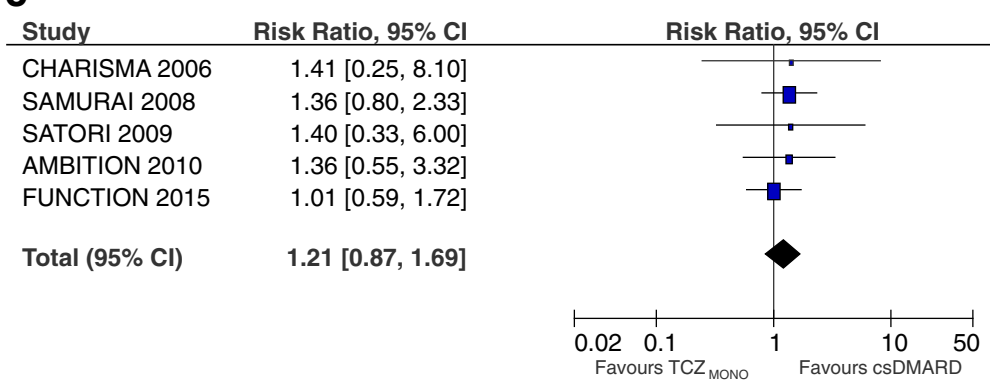

Fig. 4 Forest plots of serious adverse events comparing tocilizumab combination therapy ( $\left.T C Z_{C O M B}\right)$ with tocilizumab monotherapy (TCZ MONO) (a),

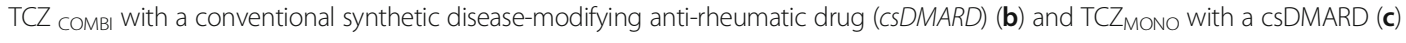

show that the efficacy of $\mathrm{TCZ}_{\mathrm{MONO}}$ is nearly equivalent to $\mathrm{TCZ}_{\mathrm{COMBI}}$ in the management of active $\mathrm{RA}$. Although the effect estimate for achieving DAS28 $<2.6$ and ACR50 response was significantly higher with the $\mathrm{TCZ}_{\mathrm{COMBI}}$ strategy, this is at the cost of a significant increase in the risk of SAEs when compared to $\mathrm{TCZ}_{\mathrm{MONO}}$. Thus, if patients do not achieve the treatment target after initiating csDMARD therapy because of intolerance, switching to $\mathrm{TCZ}_{\mathrm{MONO}}$ is a feasible option in clinical practice, whereas similar efficacy can be expected compared to inadequate responders to csDMARDs who switch to add-on $\mathrm{TCZ}_{\mathrm{COMBI}}$ therapy.

TCZ is the first biologic agent to show comparable efficacy when used as monotherapy or combination therapy, whereas other biologic agents have consistently been reported to be significantly less effective when used as monotherapy [30-33]. To determine if $\mathrm{TCZ}_{\mathrm{MONO}}$ is also superior to other biologic monotherapies, it is necessary to make direct comparisons in patients who require this therapy. However, the ADACTA study [9] is hitherto the only head-to-head randomized trial comparing two different biologic monotherapies (adalimumab versus TCZ), whereas TCZ was found to be superior for reducing signs and symptoms of RA in patients for whom continuation of MTX was discouraged. These findings are endorsed in a network analysis indirectly comparing biologic monotherapy trials, whereas TCZ has also been associated with greater efficacy than aTNFo [34]. However, further research is needed to determine the potential superiority of TCZ as first-line biologic therapy.

The results of our meta-analyses confirm and extend findings from previous studies. Although systematic reviews often do not directly lead to new insights, our review provides stronger evidence compared to clinical 
Table 2 Efficacy and safety outcomes of tocilizumab $8 \mathrm{mg} / \mathrm{kg}$ monotherapy and combination therapy comprising tocilizumab and a conventional synthetic disease modifying anti-rheumatic drug

\begin{tabular}{|c|c|c|c|c|c|c|}
\hline \multirow[b]{2}{*}{ Outcome measures } & \multicolumn{3}{|c|}{ Meta-analysis } & \multicolumn{3}{|c|}{ Sensitivity analyses ${ }^{a}$} \\
\hline & $\mathrm{RR}$ & $95 \% \mathrm{Cl}$ & $P$ & RR & $95 \% \mathrm{Cl}$ & $P$ \\
\hline \multicolumn{7}{|l|}{$\mathrm{TCZ}_{\mathrm{COMBI}}$ vs. TCZ MONO } \\
\hline DAS $28<2.6$ & 1.21 & $1.09,1.36$ & $<0.001$ & 1.20 & $1.07,1.34$ & 0.002 \\
\hline ACR20 & 1.05 & $0.99,1.12$ & 0.11 & 1.05 & $0.98,1.11$ & 0.17 \\
\hline ACR50 & 1.14 & $1.03,1.26$ & 0.008 & 1.13 & $1.02,1.25$ & 0.02 \\
\hline ACR70 & 1.19 & $0.94,1.51$ & 0.14 & 1.12 & $0.95,1.33$ & 0.19 \\
\hline AEs & 1.08 & $0.97,1.21$ & 0.17 & 1.09 & $0.86,1.38$ & 0.48 \\
\hline SAES & 1.40 & $1.03,1.92$ & 0.03 & 1.34 & $0.79,2.27$ & 0.27 \\
\hline \multicolumn{7}{|c|}{ TCZ } \\
\hline DAS28 $<2.6$ & 8.77 & $4.10,18.75$ & $<0.001$ & 10.39 & $4.38,24.65$ & $<0.001$ \\
\hline ACR20 & 2.10 & $1.48,2.99$ & $<0.001$ & 2.15 & $1.45,3.19$ & $<0.001$ \\
\hline ACR50 & 3.00 & $1.80,4.99$ & $<0.001$ & 3.24 & $1.82,5.78$ & $<0.001$ \\
\hline ACR70 & 5.32 & $2.31,12.25$ & $<0.001$ & 6.23 & $2.29,16.93$ & $<0.001$ \\
\hline AEs & 1.12 & $1.06,1.18$ & $<0.001$ & 1.14 & $1.07,1.20$ & $<0.001$ \\
\hline SAES & 1.21 & $0.91,1.60$ & 0.19 & 1.13 & $0.80,1.60$ & 0.48 \\
\hline \multicolumn{7}{|c|}{$\mathrm{TCZ}_{\text {MONO }}$ vs. CsDMARD } \\
\hline DAS $28<2.6$ & 3.95 & $2.23,7.00$ & $<0.001$ & 4.50 & $2.34,8.64$ & $<0.001$ \\
\hline ACR20 & 1.68 & $1.21,2.32$ & 0.002 & 1.71 & $1.18,2.48$ & 0.005 \\
\hline ACR50 & 1.87 & $1.19,2.95$ & 0.007 & 2.01 & $1.18,3.42$ & 0.01 \\
\hline ACR70 & 2.11 & $1.18,3.78$ & 0.01 & 2.49 & $1.29,4.81$ & 0.007 \\
\hline AEs & 1.08 & $1.01,1.15$ & 0.03 & 1.13 & $0.92,1.39$ & 0.24 \\
\hline SAES & 1.21 & $0.87,1.69$ & 0.26 & 1.37 & $0.64,2.93$ & 0.42 \\
\hline
\end{tabular}

${ }^{a}$ The CHARISMA study was excluded from all meta-analyses; the FUNCTION study was excluded from all meta-analyses of safety outcomes (adverse events (AEs) and serious AEs (SAEs)); the SAMURAI study was excluded from meta-analyses of the safety of tocilizumab monotherapy (TCZ disease-modifying anti-rheumatic drug (csDMARD); the SURPRISE study was excluded (from meta-analyses of the safety of tocilizumab combination therapy ( $\left(\mathrm{TCZ}_{\mathrm{COMB}}\right)$ vs. $\mathrm{TCZ}_{\text {MONo. }} R R$ relative risk, $\mathrm{Cl}$ confidence interval, DAS28 Disease Activity Score in 28 joints, $A C R$ American college of Rheumatology, $A E s$ adverse events, SAEs serious AEs

trials and also has several other advantages. Meta-analyses are able to examine rare events more adequately by accruing data from several studies and therefore increasing the likelihood of finding relevant differences. The majority of the studies included in our systematic review had samples sizes calculated on the basis of efficacy outcomes, which are frequently observed, and were thus not powered to detect significant differences in the incidence of less frequent events such as SAEs.

In this review, five studies $[10,19,20,27,28]$ were included that compared $\mathrm{TCZ}_{\mathrm{MONO}}$ with $\mathrm{TCZ}_{\mathrm{COMBI}}$ and none of them demonstrated a significant difference between the two strategies in the incidence of SAEs. However, our meta-analyses showed a significantly higher risk (RR 1.40; $95 \% 1.03,1.92, p=0.03$ ) of SAEs with the $\mathrm{TCZ}_{\mathrm{COMBI}}$ strategy. By pooling effect estimates, metaanalyses are better able to determine the true efficacy and safety of therapy compared to individual studies, and are therefore essential for making future recommendations on the management of RA. Apart from more adequately estimating the benefit and harms of a therapy, meta-analyses are also able to evaluate the inconsistency between studies and quantify treatment effects, and are invaluable to practitioners, as they summarize the latest evidence [35, 36].

In our meta-analysis, TCZ was only assessed at a dose of $8 \mathrm{mg} / \mathrm{kg}$. Previous clinical trials [10, 12, 14, 17, 20, 37] consistently report superior efficacy of $8 \mathrm{mg} / \mathrm{kg}$ compared to $4 \mathrm{mg} / \mathrm{kg}$ in decreasing disease activity and preventing radiographic evidence of progression. The findings of these studies were confirmed in several systematic reviews, whereas meta-analyses have shown significantly greater efficacy with the $8-\mathrm{mg} / \mathrm{kg}$ dose $[38,39]$. In another review performed by Campbell et al. [40], the risk of AEs was not significantly different between the two different doses, which supports the superior dose-response relationship of the higher dose. TCZ inhibits the binding of IL-6 to its receptor, which has its direct effects on acute phase reactants (APR) such as CRP and ESR. Although reduction in APR was sustained in patients treated with 
$8 \mathrm{mg} / \mathrm{kg}$, these decreases were not maintained with $4 \mathrm{mg} / \mathrm{kg}$, possibly indicating less sufficient targeting of the IL- 6 pathway and therefore resulting in less efficacy $[14,17,41]$.

In this review we also evaluated the efficacy and safety of both TCZ strategies versus csDMARD therapy. According to current guidelines, newly diagnosed patients with RA should receive csDMARD therapy as the first-line treatment, and in the case of inefficacy or intolerability, switch to or add a biologic DMARD. Before making assumptions as to whether $\mathrm{TCZ}_{\mathrm{MONO}}$ or $\mathrm{TCZ}_{\mathrm{COMBI}}$ would be adequate to decrease symptoms in patients not achieving the treatment target with csDMARD therapy alone, it is necessary to compare the efficacy of both these strategies with the standard of care. Although a proportion of patients did not initially achieve remission with csDMARD therapy, this does not necessary mean that this therapy was not effective at all. Thus, the efficacy of $\mathrm{TCZ}_{\mathrm{MONO}}$ could be not significantly better than that of the csDMARD therapy in these patients who are more difficult to treat, and then, switching to $\mathrm{TCZ}_{\mathrm{MONO}}$ would thus not be a good option for patients who do not respond to csDMARDs.

Although this is the first meta-analysis comparing $\mathrm{TCZ}_{\mathrm{MONO}}$ with csDMARD therapy, $\mathrm{TCZ}_{\mathrm{COMBI}}$ has already been compared to csDMARD therapy in previous meta-analyses [38-40]. Our meta-analysis of this treatment-control combination differs to these studies because: (1) several new large RCTs have been published; (2) 24-week results were obtained from studies with longer follow up; and (3) we performed sensitivity analyses to assess the heterogeneity between studies. The results of our meta-analyses show that switching to $\mathrm{TCZ}_{\mathrm{MONO}}$ and $\mathrm{TCZ}_{\mathrm{COMBI}}$ therapy is superior to continuing csDMARD therapy alone in patients with active RA. However, the treatment effect of TCZ is likely to be enhanced by the study design of the RCTs, because in studies with a csDMARD comparator group [10-18], patients were already on this therapy prior to inclusion, except in the FUNCTION study [27], whereas $81 \%$ of the patients were DMARD-naïve.

TCZ, as monotherapy or combination therapy, has also shown to be effective as first-line therapy in newly diagnosed treatment-naïve patients with RA. In U-Act-Early [42], a recently published randomized, multicenter, threeparallel-arm, double-blind, treat-to-target study, DMARDnaive patients were allocated to start on $\mathrm{TCZ}_{\mathrm{MONO}}$, $\mathrm{TCZ}_{\mathrm{COMBI}}$ or MTX therapy. Both $\mathrm{TCZ}$ strategies were found to be more effective in achieving sustained remission $\left(\mathrm{TCZ}_{\mathrm{COMBI}} 86 \%, \mathrm{TCZ}_{\mathrm{MONO}} 83 \%\right.$ ) compared to $\operatorname{MTX}(44 \%, p<0.001)$. This study endorses the immediate initiation of TCZ in early RA, with or without MTX, when used in a treat-to-target approach, including tapering of medication when remission is achieved.
Several weaknesses are apparent in this metaanalyses, which will be addressed. First, studies included in our review were heterogeneous in respect to csDMARD therapy. The majority used MTX monotherapy $[10,12,14-17,19]$ as control therapy; however, in four studies $[11,13,18,20]$ several csDMARDs were permitted. Furthermore, MTX was given at a lower dose in Japanese studies $[11,15]$ compared to studies performed in Caucasian populations $[10,12,14,16,17,19]$ because of the different health regulations. Second, the treatment efficacy of TCZ as assessed using the DAS28 should be interpreted with caution because of the prominent effect of IL-6 inhibition by TCZ on APR, which can lead to exaggerated response rates when compared to csDMARD or other bDMARD therapies. Thus, we also used ACR response criteria for evaluating efficacy, which yielded similar findings when compared to DAS28, endorsing the superiority of switching to $\mathrm{TCZ}_{\mathrm{MONO}}$ or $\mathrm{TCZ} \mathrm{Z}_{\mathrm{COMBI}}$ therapy compared to continuing csDMARD therapy. Third, studies also differed with respect to study duration. Sensitivity analyses were performed to assess whether studies with follow up shorter or longer than 24 weeks reported systematically different treatment effects. In general, the effect estimates and the between-study variation did not change significantly and thus, does not change our previous conclusions. However, it may indicate that other factors such as demographic characteristics (e.g., early versus established RA) and prior DMARD use (e.g., MTX-naïve versus non-naive patients) probably contribute more to the heterogeneity. Unfortunately because of the limited number of studies included in this review, we were not able to explore these potential sources of between-study variability.

\section{Conclusions}

In conclusion, in the management of active RA, switching to $\mathrm{TCZ}_{\mathrm{MONO}}$ is a good option for patients who cannot tolerate csDMARDs, whereas similar efficacy can be expected compared to $\mathrm{TCZ}_{\mathrm{COMBI}}$ therapy. Although $\mathrm{TCZ}_{\mathrm{COMBI}}$ is marginally superior to $\mathrm{TCZ}_{\mathrm{MONO}}$ in terms of achieving DAS2 $8<2.6$ and ACR50 response, this is at the cost of a significantly increased risk of SAEs. TCZ is the first biologic agent to show comparable efficacy when used as monotherapy or combination therapy.

\section{Additional files}

Additional file 1: Detailed description of the full search strategy. (DOCX $13 \mathrm{~kb}$ )

Additional file 2: Forest plots of American College of Rheumatology 20 (a), 50 (b), and 70 (c) responses. Meta-analyses of ACR responses for the following treatment-control combinations: (1) TCZ $Z_{\text {MONO Vs. }} \mathrm{TCZ}_{\text {COMBli }}$ (2) $\mathrm{TCZ}_{\text {MONO }}$ vs. CsDMARD; and (3) TCZ 
Additional file 3: Funnel plots of a DAS28 <2.6, b ACR20, c ACR50 responses, d ACR70 responses, e AEs and f SAEs. Funnel plots of efficacy and safety outcomes for the following treatment-control combinations: (1) TCZ MONO Vs. TCZ COMBii (2) TCZ MONO Vs. CSDMARD; and (3) TCZ COMBI Vs. csDMARD. (DOCX $63 \mathrm{~kb})$

Additional file 4: Variance in heterogeneity per meta-analysis. Table showing the heterogeneity between studies of DAS28 < 2.6, ACR 20/50/ 70 responses, AEs and SAEs. (DOCX $17 \mathrm{~kb}$ )

Additional file 5: Assessment of quality of studies (+ indicates low risk of bias, - indicates high risk of bias and? indicates the risk of bias is unclear). Table showing the risk of bias for each study included in this meta-analyses. (DOCX $30 \mathrm{~kb}$ )

\section{Abbreviations}

ACR: American College of Rheumatology; ACR20/50/70: $20 \% / 50 \% / 70 \%$ improvement according to American College of Rheumatology criteria; AE: Adverse event; APR: Acute phase reactants; aTNFa: Anti-tumor necrosis factor alpha; bDMARD: Biological disease-modifying anti-rheumatic drug; CENTRAL: Cochrane Central Register of Controlled Trials; Cl: Confidence interval; CRP: C-reactive protein; CSDMARD: Conventional synthetic diseasemodifying anti-rheumatic drug; DAS28: Disease Activity Score in 28 joints; DMARD: Disease-modifying anti-rheumatic drug; EMBASE: Exerpta Medica Database; ESR: Erythrocyte sedimentation rate; EULAR: European League Against Rheumatism; HAQ: Health Assessment Questionnaire; IL-6: Interleukin-6; MeSH: Medical subject headings; MTX: Methotrexate; PRISMA: Preferred Reporting Items for Systematic Reviews and Meta-analyses; RA: Rheumatoid arthritis; RCT: Randomized controlled trial; RR: Relative risk; SAE: Serious adverse event; TCZ: Tocilizumab; TCZ TCZ $_{\text {MONo: Tocilizumab monotherapy }}$

\section{Acknowledgements}

Not applicable.

\section{Funding}

Not applicable.

\section{Availability of data and materials}

Data used for the meta-analysis was obtained from the published papers and clinicaltrials.gov as follows : Kaneko et al. (SURPRISE 2016) [28], Clinicaltrails.gov: NCT01120366; Burmester et al. (FUNCTION 2015) [27], Clinicaltrails.gov: NCT01007435; Dougados et al. (ACT-RAY 2013) [19], Clinicaltrials.gov: NCT00810199; Weinblatt et al. (ACT-STAR 2013) [20], Clinicaltrials.gov: NCT00891020; Yazici et al. (ROSE 2012) [18], Clinicaltrials.gov: NCT00531817; Kremer et al. (LITHE 2011) [17], Clinicaltrials.gov: NCT00106535; Jones et al. (AMBITION 2010) [16], Clinicaltrials.gov: NCT00109408; Nishimoto et al. (SATORI 2009) [15], Clinicaltrials.gov: NCT00144521; Genovese et al. (TOWARD 2008) [13], Clinicaltrials.gov: NCT00106574; Smolen et al. (OPTION 2008) [14], Clinicaltrials.gov: NCT00106548; Emery et al. (RADIATE 2008) [12]; Nishimoto et al. (SAMURAI 2007) [11], Clinicaltrials.gov: NCT00144508; Maini et al. CHARISMA 2006 [10].

\section{Authors' contributions}

XMT: study design, data collection, data interpretation and writing. ACAM: data collection, data interpretation and writing. JWJB: study design, data interpretation and writing. FPJL: study design, data interpretation and writing. JWGJ: study design, data interpretation and writing. All authors can defend the manuscript contents, have read the manuscript prior to its submission for publication and agree with its contents.

\section{Authors' information}

Not applicable.

\section{Competing interests}

All authors have participated in the U-Act-Early study [42] but have no non-financial competing interests. JWJB previously received research grants (to his department) and consultancy fees from AbbVie, BMS, Crescendo, MSD, Mundipharma, Pfizer, Roche, Sun and UCB.

\section{Consent for publication}

Not applicable.

\section{Ethical approval and consent to participate}

Not applicable.

Received: 10 May 2016 Accepted: 2 September 2016

Published online: 22 September 2016

\section{References}

1. Smolen JS, Landewe R, Breedveld FC, Buch M, Burmester G, Dougados M, Emery P, Gaujoux-Viala C, Gossec L, Nam J, et al. EULAR recommendations for the management of rheumatoid arthritis with synthetic and biological disease-modifying antirheumatic drugs: 2013 update. Ann Rheum Dis. 2014; 73(3):492-509.

2. Singh JA, Furst DE, Bharat A, Curtis JR, Kavanaugh AF, Kremer JM, Moreland LW, O'Dell J, Winthrop KL, Beukelman T, et al. 2012 update of the 2008 American College of Rheumatology recommendations for the use of disease-modifying antirheumatic drugs and biologic agents in the treatment of rheumatoid arthritis. Arthritis Care Res. 2012;64(5):625-39.

3. Gaujoux-Viala C, Gossec L, Cantagrel A, Dougados M, Fautrel B, Mariette X, Nataf H, Saraux A, Trope S, Combe B, et al. Recommendations of the French Society for Rheumatology for managing rheumatoid arthritis. Joint Bone Spine. 2014;81(4):287-97.

4. Listing J, Strangfeld A, Rau R, Kekow J, Gromnica-Ihle E, Klopsch T, Demary W, Burmester GR, Zink A. Clinical and functional remission: even though biologics are superior to conventional DMARDs overall success rates remain low-results from RABBIT, the German biologics register. Arthritis Res Ther. 2006;8(3):R66.

5. Soliman MM, Ashcroft DM, Watson KD, Lunt M, Symmons DP, Hyrich KL. British Society for Rheumatology Biologics R. Impact of concomitant use of DMARDs on the persistence with anti-TNF therapies in patients with rheumatoid arthritis: results from the British Society for Rheumatology Biologics Register. Ann Rheum Dis. 2011;70(4):583-9.

6. Nikiphorou E, Negoescu A, Fitzpatrick JD, Goudie CT, Badcock A, Ostor AJ, Malaviya AP. Indispensable or intolerable? Methotrexate in patients with rheumatoid and psoriatic arthritis: a retrospective review of discontinuation rates from a large UK cohort. Clin Rheumatol. 2014;33(5):609-14.

7. Salliot C, van der Heijde D. Long-term safety of methotrexate monotherapy in patients with rheumatoid arthritis: a systematic literature research. Ann Rheum Dis. 2009;68(7):1100-4.

8. Singh JA, Beg S, Lopez-Olivo MA. Tocilizumab for rheumatoid arthritis: a Cochrane systematic review. J Rheumatol. 2011;38(1):10-20.

9. Gabay C, Emery P, van Vollenhoven R, Dikranian A, Alten R, Pavelka K, Klearman M, Musselman D, Agarwal S, Green J, et al. Tocilizumab monotherapy versus adalimumab monotherapy for treatment of rheumatoid arthritis (ADACTA): a randomised, double-blind, controlled phase 4 trial. Lancet. 2013;381(9877):1541-50.

10. Maini RN, Taylor PC, Szechinski J, Pavelka K, Broll J, Balint G, Emery P, Raemen F, Petersen J, Smolen J, et al. Double-blind randomized controlled clinical trial of the interleukin-6 receptor antagonist, tocilizumab, in European patients with rheumatoid arthritis who had an incomplete response to methotrexate. Arthritis Rheum. 2006;54(9):2817-29.

11. Nishimoto N, Hashimoto J, Miyasaka N, Yamamoto K, Kawai S, Takeuchi T, Murata N, van der Heijde D, Kishimoto T. Study of active controlled monotherapy used for rheumatoid arthritis, an IL-6 inhibitor (SAMURAI): evidence of clinical and radiographic benefit from an $\mathrm{x}$ ray reader-blinded randomised controlled trial of tocilizumab. Ann Rheum Dis. 2007;66(9):1162-7.

12. Emery P, Keystone E, Tony HP, Cantagrel A, van Vollenhoven R, Sanchez A, Alecock E, Lee J, Kremer J. IL-6 receptor inhibition with tocilizumab improves treatment outcomes in patients with rheumatoid arthritis refractory to anti-tumour necrosis factor biologicals: results from a 24-week multicentre randomised placebo-controlled trial. Ann Rheum Dis. 2008; 67(11):1516-23.

13. Genovese MC, McKay JD, Nasonov EL, Mysler EF, da Silva NA, Alecock E, Woodworth T, Gomez-Reino JJ. Interleukin-6 receptor inhibition with tocilizumab reduces disease activity in rheumatoid arthritis with inadequate response to disease-modifying antirheumatic drugs: the tocilizumab in combination with traditional disease-modifying antirheumatic drug therapy study. Arthritis Rheum. 2008;58(10):2968-80.

14. Smolen JS, Beaulieu A, Rubbert-Roth A, Ramos-Remus C, Rovensky J, Alecock E, Woodworth T, Alten R. Effect of interleukin-6 receptor inhibition with tocilizumab in patients with rheumatoid arthritis (OPTION study): a double-blind, placebo-controlled, randomised trial. Lancet. 2008;371(9617): 987-97. 
15. Nishimoto N, Miyasaka N, Yamamoto K, Kawai S, Takeuchi T, Azuma J, Kishimoto T. Study of active controlled tocilizumab monotherapy for rheumatoid arthritis patients with an inadequate response to methotrexate (SATORI): significant reduction in disease activity and serum vascular endothelial growth factor by IL-6 receptor inhibition therapy. Mod Rheumatol. 2009;19(1):12-9.

16. Jones G, Sebba A, Gu J, Lowenstein MB, Calvo A, Gomez-Reino JJ, Siri DA, Tomsic M, Alecock E, Woodworth T, et al. Comparison of tocilizumab monotherapy versus methotrexate monotherapy in patients with moderate to severe rheumatoid arthritis: the AMBITION study. Ann Rheum Dis. 2010;69(1):88-96.

17. Kremer JM, Blanco R, Brzosko M, Burgos-Vargas R, Halland AM, Vernon E, Ambs $P$, Fleischmann R. Tocilizumab inhibits structural joint damage in rheumatoid arthritis patients with inadequate responses to methotrexate: results from the double-blind treatment phase of a randomized placebocontrolled trial of tocilizumab safety and prevention of structural joint damage at one year. Arthritis Rheum. 2011;63(3):609-21.

18. Yazici $Y$, Curtis JR, Ince A, Baraf $H$, Malamet $R L$, Teng LL, Kavanaugh A. Efficacy of tocilizumab in patients with moderate to severe active rheumatoid arthritis and a previous inadequate response to diseasemodifying antirheumatic drugs: the ROSE study. Ann Rheum Dis. 2012; 71(2):198-205.

19. Dougados M, Kissel K, Sheeran T, Tak PP, Conaghan PG, Mola EM, Schett G, Amital H, Navarro-Sarabia F, Hou A, et al. Adding tocilizumab or switching to tocilizumab monotherapy in methotrexate inadequate responders: 24week symptomatic and structural results of a 2-year randomised controlled strategy trial in rheumatoid arthritis (ACT-RAY). Ann Rheum Dis. 2013;72(1): 43-50.

20. Weinblatt ME, Kremer J, Cush J, Rigby W, Teng LL, Devenport J, Singh N, Lepley D, Genovese MC. Tocilizumab as monotherapy or in combination with nonbiologic disease-modifying antirheumatic drugs: twenty-four-week results of an open-label, clinical practice study. Arthritis Care Res. 2013;65(3): 362-71.

21. Liberati A, Altman DG, Tetzlaff J, Mulrow C, Gotzsche PC, loannidis JP, Clarke M, Devereaux PJ, Kleijnen J, Moher D. The PRISMA statement for reporting systematic reviews and meta-analyses of studies that evaluate health care interventions: explanation and elaboration. Ann Intern Med. 2009;151(4):W65-94.

22. Aletaha D, Neogi T, Silman AJ, Funovits J, Felson DT. Bingham 3rd CO, Birnbaum NS, Burmester GR, Bykerk VP, Cohen MD, et al. 2010 rheumatoid arthritis classification criteria: an American College of Rheumatology/ European League Against Rheumatism collaborative initiative. Ann Rheum Dis. 2010;69(9):1580-8.

23. Arnett FC, Edworthy SM, Bloch DA, McShane DJ, Fries JF, Cooper NS, Healey LA Kaplan SR, Liang MH, Luthra HS, et al. The American Rheumatism Association 1987 revised criteria for the classification of rheumatoid arthritis. Arthritis Rheum. 1988;31(3):315-24.

24. Egger M, Smith GD, Altman DG. Systematic reviews in health care: metaanalysis in context (2008). 2nd ed. BMJ Books. 2008. doi:10.1002/ 97804706939263.

25. Borenstein M, Hedges LV, Higgins JPT, Rothstein HR. Introduction to metaanalysis. Chichester: John Wiley \& Sons, Ltd; 2009. doi:10.1002/ 9780470743386

26. Sterne JA, Gavaghan D, Egger M. Publication and related bias in metaanalysis: power of statistical tests and prevalence in the literature. J Clin Epidemiol. 2000;53(11):1119-29.

27. Burmester GR, Rigby WF, van Vollenhoven RF, Kay J, Rubbert-Roth A, Kelman A, Dimonaco S, Mitchell N. Tocilizumab in early progressive rheumatoid arthritis: FUNCTION, a randomised controlled trial. Ann Rheum Dis. 2016;75(6):1081-91. doi:10.1136/annrheumdis-2015-207628.

28. Kaneko Y, Atsumi T, Tanaka Y, Inoo M, Kobayashi-Haraoka H, Amano K, Miyata M, Murakawa Y, Yasuoka H, Hirata S, et al. Comparison of adding tocilizumab to methotrexate with switching to tocilizumab in patients with rheumatoid arthritis with inadequate response to methotrexate: 52-week results from a prospective, randomised, controlled study (SURPRISE study). Ann Rheum Dis. 2016. doi:10.1136/annrheumdis-2015-208426. epub ahead of print.

29. Terrin N, Schmid CH, Lau J. In an empirical evaluation of the funnel plot, researchers could not visually identify publication bias. J Clin Epidemiol. 2005;58(9):894-901.

30. Breedveld FC, Weisman MH, Kavanaugh AF, Cohen SB, Pavelka K, van Vollenhoven R, Sharp J, Perez JL, Spencer-Green GT. The PREMIER study: A multicenter, randomized, double-blind clinical trial of combination therapy with adalimumab plus methotrexate versus methotrexate alone or adalimumab alone in patients with early, aggressive rheumatoid arthritis who had not had previous methotrexate treatment. Arthritis Rheum. 2006; 54(1):26-37

31. van der Heijde D, Klareskog $L$, Rodriguez-Valverde V, Codreanu C, Bolosiu H, Melo-Gomes J, Tornero-Molina J, Wajdula J, Pedersen R, Fatenejad S, et al. Comparison of etanercept and methotrexate, alone and combined, in the treatment of rheumatoid arthritis - Two-year clinical and radiographic results from the TEMPO study, a double-blind, randomized trial. Arthritis Rheum. 2006;54(4):1063-74.

32. Emery $P$, Breedveld F, van der Heijde D, Ferraccioli G, Dougados $M$, Robertson D, Pedersen R, Koenig AS, Freundlich B, Combination of M, et al. Two-year clinical and radiographic results with combination etanerceptmethotrexate therapy versus monotherapy in early rheumatoid arthritis: a two-year, double-blind, randomized study. Arthritis Rheum. 2010;62(3):674-82.

33. Edwards JC, Szczepanski L, Szechinski J, Filipowicz-Sosnowska A, Emery P, Close DR, Stevens RM, Shaw T. Efficacy of B-cell-targeted therapy with rituximab in patients with rheumatoid arthritis. N Engl J Med. 2004;350(25): 2572-81.

34. Jansen JP, Buckley F, Dejonckheere F, Ogale S. Comparative efficacy of biologics as monotherapy and in combination with methotrexate on patient reported outcomes (PROs) in rheumatoid arthritis patients with an inadequate response to conventional DMARDs-a systematic review and network meta-analysis. Health Qual Life Outcomes. 2014;12:102.

35. Gopalakrishnan S, Ganeshkumar P. Systematic reviews and meta-analysis: understanding the best evidence in primary healthcare. J Fam Med Prim Care. 2013;2(1):9-14

36. Cook DJ, Mulrow CD, Haynes RB. Systematic reviews: synthesis of best evidence for clinical decisions. Ann Intern Med. 1997;126(5):376-80.

37. Schoels MM, van der Heijde D, Breedveld FC, Burmester GR, Dougados M, Emery P, Ferraccioli G, Gabay C, Gibofsky A, Gomez-Reino JJ, et al. Blocking the effects of interleukin- 6 in rheumatoid arthritis and other inflammatory rheumatic diseases: systematic literature review and meta-analysis informing a consensus statement. Ann Rheum Dis. 2013:72(4):583-9.

38. Navarro G, Taroumian S, Barroso N, Duan L, Furst D. Tocilizumab in rheumatoid arthritis: a meta-analysis of efficacy and selected clinical conundrums. Semin Arthritis Rheum. 2014;43(4):458-69.

39. An MM, Zou Z, Shen H, Zhang JD, Cao YB, Jiang YY. The addition of tocilizumab to DMARD therapy for rheumatoid arthritis: a meta-analysis of randomized controlled trials. Eur J Clin Pharmacol. 2010;66(1):49-59.

40. Campbell L, Chen C, Bhagat SS, Parker RA, Ostor AJ. Risk of adverse events including serious infections in rheumatoid arthritis patients treated with tocilizumab: a systematic literature review and meta-analysis of randomized controlled trials. Rheumatology (Oxford). 2011;50(3):552-62.

41. Smolen JS, Schoels MM, Nishimoto N, Breedveld FC, Burmester GR, Dougados M, Emery P, Ferraccioli G, Gabay C, Gibofsky A, et al. Consensus statement on blocking the effects of interleukin- 6 and in particular by interleukin-6 receptor inhibition in rheumatoid arthritis and other inflammatory conditions. Ann Rheum Dis. 2013;72(4):482-92.

42. Bijlsma JW, Welsing PM, Woodworth TG, Middelink LM, Petho-Schramm A, Bernasconi C, Borm ME, Wortel CH, Ter Borg EJ, Jahangier ZN, et al. Early rheumatoid arthritis treated with tocilizumab, methotrexate, or their combination (U-Act-Early): a multicentre, randomised, double-blind, doubledummy, strategy trial. Lancet. 2016;388(10042):343-55.

\section{Submit your next manuscript to BioMed Central and we will help you at every step:}

- We accept pre-submission inquiries

- Our selector tool helps you to find the most relevant journal

- We provide round the clock customer support

- Convenient online submission

- Thorough peer review

- Inclusion in PubMed and all major indexing services

- Maximum visibility for your research

Submit your manuscript at www.biomedcentral.com/submit 